\title{
Assessing patient-centred care for chronic pain: Validation of a new research paradigm
}

\author{
Emilie Paul-Savoie PhD(c) ${ }^{1}$, Patricia Bourgault RN PhD ${ }^{1}$, Emilie Gosselin RN MSc ${ }^{1}$, \\ Stéphane Potvin $\mathrm{PhD}^{2}$, Sylvie Lafrenaye $\mathrm{MD} \mathrm{PhD}^{3}$
}

\begin{abstract}
E Paul-Savoie, P Bourgault, E Gosselin, S Potvin, S Lafrenaye. Assessing patient-centred care for chronic pain: Validation of a new research paradigm. Pain Res Manag 2015;20(4):183-188.
\end{abstract}

BACKGROUND: Chronic pain is a complex phenomenon resulting from biological, psychological and social factors, and the use of patientcentred care (PCC) appears to be a promising avenue for its treatment. Various methods have been used for measuring PCC in nurses and physicians (caregivers); however, methodological problems have been raised following the observation of real clinical encounters or standardized patient simulations. The development of new strategies is required.

OBJECTIVE: To develop and validate an observation scale for the assessment of PCC in caregivers, using standardized videos of real patients with chronic pain.

METHODS: An expert panel developed five videos and the Sherbrooke Observation Scale of Patient-Centered Care (SOS-PCC), which were tested in a sample of 21 nurses and 21 physicians working with chronic pain patients. The content validity, internal consistency and inter-rater reliability of the SOS-PCC were assessed.

RESULTS: The expert panel was satisfied with the content validity of the SOS-PCC. Results revealed good internal consistency (Cronbach's alpha = 0.88 ) and inter-rater reliability (intraclass coefficient $=0.93$ ) for this scale. CONCLUSIONS: To the authors' knowledge, the SOS-PCC is the first instrument available in French to assess PCC behaviour of caregivers using videos of real patients with chronic pain. The psychometric qualities of these instruments are good. Future studies will need to assess this instrument with other populations of caregivers.

Key Words: Assessment; Chronic pain; Nurse; Patient care; Patient-centred care; Physician

Chronic pain is recognized as a major public health problem throughout the world (1). Its magnitude in Canada is considerable, with a high prevalence among adults (ranging from $15 \%$ to $29 \%)(2,3)$. Individuals with chronic pain are more likely to be absent from work $(4,5)$ and consult health professionals frequently (6), resulting in a considerable economic burden $(7,8)$. Moreover, chronic pain is a complex phenomenon resulting from several factors including biological, psychological and social factors (8), and treatments must consider all of these aspects simultaneously to be effective (9). Thus, the use of patient-centred care (PCC) appears to be a promising avenue. Moreover, it has been suggested that interdisciplinary PCC is paramount for pain management (10). In the context of medicine, PCC has four dimensions: patient-as-person; biopsychosocial perspective; sharing power and responsibility; and therapeutic alliance (11-13). These four dimensions are also found in the conceptual framework of McCormack and McCance (14), used in the nursing

\section{L'évaluation des soins de la douleur chronique axés sur les patients : la validation d'un nouveau paradigme de recherche}

HISTORIQUE : La douleur chronique est un phénomène complexe attribuable à des facteurs biologiques, psychologiques et sociaux. Dans le cadre du traitement, le recours à des soins axés sur les patients (SAP) semble prometteur. Diverses méthodes ont déjà été utilisées pour mesurer les SAP chez les infirmières et les médecins (les soignants), mais des problèmes méthodologiques ont été soulevés après l'observation de véritables rencontres cliniques ou de simulations de patients standardisées. De nouvelles stratégies s'imposent.

OBJECTIF : Préparer et valider une échelle d'observation pour évaluer les SAP chez les soignants au moyen de vidéos standardisées de véritables patients souffrant de douleur chronique.

MÉTHODOLOGIE : Un groupe d'experts a préparé cinq vidéos et l'échelle d'observation de Sherbrooke des soins axés sur les patients (ÉOS-SAP), les a mises à l'essai auprès d'un échantillon de 21 infirmières et de 21 médecins qui travaillent auprès de patients atteints de douleur chronique. Il en a évalué la validité du contenu, la cohérence interne et la fiabilité interévaluateur.

RÉSULTATS : Le groupe d'experts était satisfait de la validité du contenu de l'ÉOS-SAP. Les résultats ont révélé une bonne cohérence interne (coefficient alpha de Cronbach $=0,88$ ) et une bonne fiabilité interévaluateur (coefficient de corrélation intraclasse $=0,93$ ).

CONCLUSIONS : En autant que le sachent les auteurs, l'ÉOS-SAP est le premier instrument offert en français pour évaluer le comportement des soignants à l'égard des SAP à l'aide de vidéos de véritables patients souffrant de douleur chronique. D'autres études devront porter sur l'évaluation de cette échelle auprès d'autres populations de soignants.

discipline. In recent years, empirical evidence has demonstrated that PCC is associated with many clinical benefits for patients (15-18) and their families (19), particularly in the context of chronic pain $(20,21)$. Qualitative findings suggest that PCC with chronic pain patients allows nurses to provide improved assessment, anticipatory guidance and coaching (21). PCC may also reduce the use of health care resources and health care costs $(22,23)$.

Although many studies support the benefits of PCC, its use in chronic pain management appears to be challenging and suboptimal (24). Moreover, the style of practice may vary among caregivers (25). In recent years, a cross-sectional observational study conducted in the Netherlands has demonstrated that the consultations in general practice appear to be more task-oriented than previously (26). More specifically, physicians provided more medical information, but expressed their concern about the patients' medical condition less frequently and were less involved in partnership building. This trend appears to

${ }^{1}$ School of Nursing, Faculty of Medicine and Health Sciences, Université de Sherbrooke, Sherbrooke; ${ }^{2}$ Centre de recherche de l'Institut

Universitaire en Santé Mentale de Montréal, Department of Psychiatry, Faculty of Medicine, Université de Montréal, Montréal;

${ }^{3}$ Department of Pediatrics, Faculty of Medicine and Health Sciences, Université de Sherbrooke, Sherbrooke, Quebec

Correspondence: Dr Sylvie Lafrenaye, Department of Pediatrics, Faculty of Medicine and Health Sciences, Université de Sherbrooke, 3001,

12 e avenue Nord, 27-4016, Sherbrooke, Quebec J1H 5N4. Telephone 819-346-1110 ext 74634, fax 819-564-5398,

e-mail sylvie.lafrenaye@usherbrooke.ca 
originate from medical school because a decline in PCC was observed in United States resident training (27).

Therefore, it is important to identify the factors that promote the use of PCC to improve academic training. To improve understanding of how caregivers could use PCC more effectively and verify the effectiveness of educational interventions, researchers need rigorous methods to capture the different components of this approach. Various methods have been used for measuring PCC in physicians including self-ratings and observer ratings $(11,16)$. It has been suggested that self-assessment instruments are more susceptible to social desirability bias (16). Moreover, observation measures are often considered to be more objective and more appropriate for the evaluation of educational interventions (16). Observation of real clinical encounters may raise ethical and methodological problems, including the inability to include standardized and repetitive visits, and the difficulty of obtaining patients' informed consent. The use of standardized patient simulations is expensive $(28,29)$ and usually simulates initial visits (30), which is not representative of encounters with chronic pain patients who tend to see the same physician on a regular basis. Videos of real chronic pain patients could overcome these difficulties by allowing a repetitive and standardized assessment of the attitude and behaviour of physicians and nurses. However, such videos are rarely described in the literature, and are not currently available in French. Moreover, although several observation instruments exist to measure PCC, no scale has been specifically designed to assess all dimensions of this concept in the context of chronic pain management using videos of real patients.

Thus, the aim of the present study was to develop and validate an observation scale for the assessment of PCC in an interdisciplinary context involving physicians and nurses (caregivers) and using standardized videos of real patients with chronic pain.

\section{Development of videos}

\section{METHODS}

Content development: It is suggested that a successful, objective case scenario must be developed by a group of experts familiar with the target area (31). In the present study, a panel of seven experts in the health care field with complementary expertise in chronic pain management participated in the development of videos. This panel was composed of a nurse, a physician, a physiotherapist, an occupational therapist, a psychologist, a psychoeducator and a $\mathrm{PhD}$ student. After a first meeting conducted in June 2012, the expert panel agreed to develop five case scenarios of patients with different chronic pain pathologies: rheumatoid arthritis; Ehlers-Danlos syndrome; long-lasting postoperative pain; fibromyalgia; and complex regional pain syndrome (CRPS). Because stigma and the presence of physical symptoms appear to influence the use of PCC (32), the expert panel opted for different pathologies to represent both apparent (rheumatoid arthritis and CRPS) and nonapparent physical symptoms (Ehlers-Danlos syndrome and fibromyalgia). Long-lasting postoperative pain was not included in this part of the analysis to allow for an equal number of videos in each group. Five patients were recruited; all were women and young ( 16 to 45 years of age). This decision was made to limit the numerous different caring attitudes toward pain (25). Before participating in the filmed interview, all patients provided written informed consent.

Videos were recorded in the most similar conditions possible with regard to camera angle, lighting and location (representating an authentic clinical environment). The patients were filmed individually and interviewd by a physician (SL) and a nurse (PB), who conducted the interviews to elicit answers about their pain and illness. Thus, the videos present a neutral clinical meeting and do not show the interviewers. The video case scenarios were edited to include only relevant parts of this neutral meeting, using patient's responses verbatim, to present a detailed patient profile including pertinent medical history, family and social history, patient affect and behaviour (33). The expert panel selected the following content: previous diagnosis; pharmacological and nonpharmacological treatments; impact of pain in everyday life; and previous experience with other caregivers.

Submission to an expert panel: All interviews were transcribed and a preliminary version ( 5 min for each video) was developed. The relevant clips of the interviews were integrated into a single video with the help of a technician to avoid abrupt cuts. All videos showed patients with a clear diagnosis of their disease that had been established for $>2$ years, except for the patient with long-lasting postoperative pain. All patients discussed their past and present pharmacological and nonpharmacological treatments. No patient was completely relieved of their pain and all were open to receive suggestions for treatment. Patients also spoke about their past experiences with professional caregivers, explaining what they liked or least appreciated. Finally, all patients discussed the impact of their condition on their social, family and financial situations. Table 1 presents patients' characteristics and video duration for each case scenario.

These preliminary versions were submitted to the same expert panel in March 2013. The research team asked the experts whether the information regarding diagnosis, pharmacological and nonpharmacological treatments, impact of pain in everyday life and previous and actual experience with caregivers were sufficiently relevant and clear for each video. The experts suggested that all these elements appeared in each video, but some redundant passages regarding pharmacological aspects could be removed. The experts believed that with all these content elements, the participant-caregivers would be able to provide PCC behaviour for each case scenario. Following this meeting, the videos were shortened, and a revised version was made and used for the pretest and the validation study.

Pretest: The revised version of each video was pretested in a sample of five participant-caregivers, including one physician and four nurses. After viewing the five videos, all participant-caregivers were asked about the management and treatment plan that they would provide to those patients. These explanations were recorded and three independent observers (PB, SL, EPS) evaluated the use of PCC demonstrated by the participant-caregivers using the new Sherbrooke Observation Scale of Patient-Centered Care (SOS-PCC) (see below). Pretest showed that participant-caregivers were able to explain the care they would provide after watching each video, and no further changes in these videos were made.

\section{Development of the SOS-PCC}

For the assessment of PCC, the development of an observational scale was necessary. The development of this observation scale followed the recommendations suggested by Streiner and Norman (34) for the development of a research instrument: survey of the literature; writing down potential statements; choosing an answer scale; selecting statements; and, finally, measuring the validity and reliability. More specifically, in the present study, we proceeded as follows: content development of the SOS-PCC after a survey of the literature; submission of the SOS-PCC to an expert panel; pretest; modifications of the SOS-PCC; and analysis of validity and reliability.

Content development: A literature review was conducted to identify the dimensions describing PCC. Relevant English and French articles were identified from searches of electronic databases, CINAHL and MEDLINE between 1980 and September 2012 for "patient-centered care" and its linguistic variations and "definition", "conceptual framework", "dimension", "medicine", "nursing" and "healthcare". The articles were selected according to relevance of the topic, year of publication (1980 to 2012) and level of credibility.

The definitions of Stewart (13) and Mead and Bower (12) are the most cited in the literature in family medicine. The definition given by Stewart (13) has six interconnected dimensions: exploring both disease and illness experience; understanding the whole person; finding a common ground regarding management; incorporating prevention and health promotion; enhancing the doctor-patient relationship; and being realistic. Regarding the definition of Mead and Bower (12), the authors identified five dimensions: biopsychosocial perspective; 
TABLE 1

\section{Video scenarios}

\begin{tabular}{lclc}
\hline Patient $^{*}$ & Age, years & Chronic pain pathology & Video duration \\
\hline 1 & 35 & Rheumatoid arthritis & $3 \min 27 \mathrm{~s}$ \\
2 & 16 & Ehlers-Danlos syndrome & $3 \min 44 \mathrm{~s}$ \\
3 & 20 & Postoperative pain & $3 \min 59 \mathrm{~s}$ \\
4 & 35 & Fibromyalgia & $4 \min 20 \mathrm{~s}$ \\
5 & 45 & Complex regional pain syndrome & $4 \min 09 \mathrm{~s}$ \\
\hline
\end{tabular}

${ }^{*}$ All female

\section{TABLE 2}

\section{Sherbrooke Observation Scale of Patient-Centered Care}

\section{Items}

Le soignant...

1 Considère les aspects biologiques [Considers biological aspects].

2 Considère les projets de vie [Considers life projects].

3 Considère les aspects psychologiques [Considers psychological aspects].

4 S'enquiert des conséquences de la condition actuelle du patient sur sa vie [Considers the impact of the current conditions on the patient's life].

5 Considère les expériences passées [Considers past experiences].

6 Désire établir une relation thérapeutique [Wishes to establish a therapeutic relationship].

7 Démontre une ouverture d'esprit, sans préjugé [Shows an open mind, without prejudice].

8 Offre une prise en charge en collaboration avec le patient [Provides a treatment plan in collaboration with the patient].

9 S'enquiert de la compréhension que le patient a de sa condition médicale actuelle [Inquires about the patient's understanding of his/her current medical condition].

A four-point Likert scale was used ("Not demonstrated" to "Strongly demonstrated")

the patient-as-person; sharing power and responsibility; the therapeutic alliance; and doctor-as-person. In the context of nursing, McCormack and McCance (14) published a conceptual framework that includes five dimensions: working with the patient's beliefs and values; engagement; sharing decision-making; having sympathetic presence; and providing for physical needs.

Analysis of these three definitions highlighted four common dimensions in PCC: biopsychosocial perspective; patient-as-person; sharing power and responsibility; and therapeutic alliance. These four dimensions are also found in the recent conceptual framework of PCC in the context of family medicine provided by Hudon et al (11). According to Stewart (13), the biopsychosocial perspective refers to a "willingness to become involved in the full range of difficulties patients bring to their doctors, and not just their biomedical problems". The holistic approach refers to providing care to an individual as a whole (biological, psychological and social aspects) and not just treating the biological disease (32). However, a biopsychosocial perspective per se is not sufficient for an overall understanding of the patient's experience of illness, which also depends on the unique biography of the patient (12). The dimension 'patient-as-person' explains that two patients can experience the same illness differently. Thus, before suggesting an effective treatment, the caregiver must understand the unique context and individual experience of the patient (35). 'Sharing power and responsibility' or 'shared decision making' are two terms used to discuss the participation of both the patient and the caregiver in the care process. Participation, which is a central term in this dimension, refers to a person who engages in decision making $(36,37)$. The decision must belong jointly to both partners - the patient and caregiver. The last dimension, 'therapeutic alliance', refers to the quality of the relationship between caregiver and could have direct impact on clinical outcomes $(38,39)$. According to Leplege et al (32), person-centredness means to respect the person 'behind' the impairment or the disease.

After reviewing the literature, the next step in the development of the SOS-PCC was to integrate these four dimensions. Initially, this

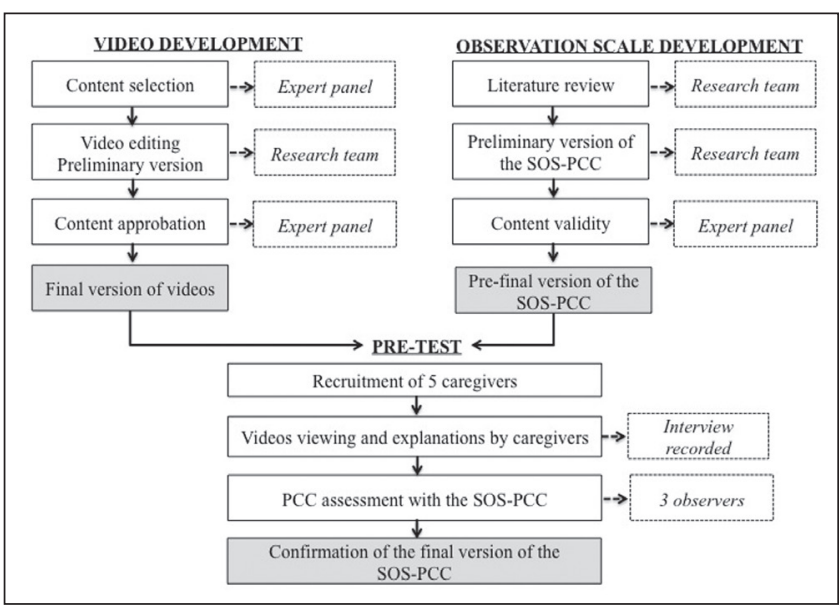

Figure 1) Development and validation process. SOS-PCC Sherbrooke Observation Scale of Patient-Centered Care

observation scale included nine items drawn from the selected definition of PCC (11). Each dimension was represented by two items, except for the biopsychosocial dimension, which was measured by three items (biological, psychological and social aspects). The final nine items are presented in Table 2. A four-point Likert scale ranging from 1 (not demonstrated) to 4 (strongly demonstrated) was chosen to ensure that the observer could not be neutral in his answers. Moreover, it enhances the reliability and efficiency of the instrument (34).

Submission to an expert panel: The same expert panel conducted the content validity testing of the SOS-PCC. The meeting was held in June 2013 and led to changes to the preliminary version. The committee of experts discussed and concluded by mutual agreement that all the items were comprehensive and relevant to the PCC concept. However, they suggested some changes to improve the understanding of the items. The number of items and the type of scale remained the same, but the wording of the items was modified to facilitate understanding and better define each dimension. In this revised version, the four dimensions of PCC have been addressed: biopsychosocial perspective (three items); 'patient-as-person' (two items); sharing power and responsibility (two items) and therapeutic alliance (two items).

Pretest: During the pre-test, five participant-caregivers watched the five videos and explained the treatment plan that they would provide; these interviews were recorded. This pretest was performed to determine whether the participant-caregivers could address the four dimensions of PCC according to the SOS-PCC. More specifically, three external observers (EPS, PB, SL) completed the scale after viewing the results of caregivers who participated in the video pretest (Figure 1). The results of the pretest revealed that observers were able to answer all nine items with the four-point Likert scale during the observation. The three observers rated the items similarly and scores were comparable, indicating that the behaviour described in each statement was relevant and observable. No further change was made.

\section{Analysis of validity and reliability}

Participants: The study was conducted from June 2013 to November 2013. The target population was caregivers (nurses and physicians) who treated patients with chronic pain in their clinical practice and worked in Quebec. A population composed of nurses and physicians was targeted because interdisciplinary pain management is recommended (10) and the concept of PCC is well defined in these disciplines (12-14). To participate in the study, the caregivers needed to: be a member of a professional association; have chronic pain patients among his/her practice; not know the patients presented in videos; and speak French. A convenience sampling was chosen and participant-caregivers were recruited through advertisements and referrals. The Scientific and Human Ethics Committee of the institution at which the study was performed approved the research protocol, and all participant-caregivers provided 
TABLE 3

Characteristics of participating nurses and physicians

\begin{tabular}{lcc}
\hline & Nurses $(\mathbf{n}=\mathbf{2 1})$ & Physicians $(\mathbf{n}=\mathbf{2 1})$ \\
\hline Age, years, mean \pm SD & $42.00 \pm 7.30$ & $50.24 \pm 12.32$ \\
Sex & & \\
Male & $5(24)$ & $8(38)$ \\
Female & $16(76)$ & $13(62)$ \\
Clinical experience, years, mean \pm SD & $16.67 \pm 7.11$ & $22.81 \pm 12.19$ \\
Education & & \\
College & $6(29)$ & \\
University & $15(71)$ & $21(100)$ \\
Specialty & & \\
Family medicine & & $10(48)$ \\
Nephrology & & $1(5)$ \\
Anesthesiology & & $3(14)$ \\
Radiology & & $1(5)$ \\
Psychiatry & & $1(5)$ \\
Rheumatology & $1(5)$ \\
Orthopedics & & $1(5)$ \\
Pediatrics & & $1(5)$ \\
Physiatry & & $2(9)$ \\
\hline
\end{tabular}

Data presented as $n(\%)$ unless otherwise indicated

written informed consent. A coding system was used to keep data confidential. After signing informed consent, a sample of 21 nurses and 21 physicians participated in the study. The validation of the SOS-PCC was conducted as part of a larger study, and this sample size was calculated to meet the objectives of the present study. This sample size meets the recommendations that suggest a range from two to 20 subjects per item (40). Participant-caregivers did not know the detailed purpose of the study to avoid social desirability bias, but they were informed that pain management was being investigated.

Procedure: All participant-caregivers watched the five videos of real patients with chronic pain and were interviewed individually. The interviewer asked the participant to explain the management and treatment plan that they would provide for each patient, and these explanations were videotaped. At the end of the study, after completing the data collection of the 42 participant-caregivers, three external observers watched the video recording of all research interviews of every participant-caregiver. The observers evaluated individually the use of PCC demonstrated by the participant-caregiver for each video using the SOS-PCC. No consensus or discussions occurred after watching the video recording. The group of observers consisted of a resident in psychiatry (FTD), a nurse (EG) and a PhD student in the health care field (EPS). The observers were selected based on their number of years of experience in the health care field ( $>5$ years) and their complementary expertise (medicine, nursing, research). To ensure the standardization in their assessment, they had previously been trained by the research team to complete the SOS-PCC during a $1.5 \mathrm{~h}$ session.

\section{Statistical analysis}

Statistical analyzes were performed using SPSS version 18.0 (IBM Corporation, USA). To describe continuous variables, means and SDs were used, whereas frequency (percentage) was used for nominal and categorical variables. To examine the internal consistency, Cronbach's alpha coefficient was calculated for each video. Finally, for inter-rater reliability, the intraclass correlation coefficient (ICC) was used. $\mathrm{P}<0.05$ was considered to be statistically significant.

\section{Participant characteristics}

\section{RESULTS}

The sample included 42 native French-speaking caregivers ranging from 27 to 67 years of age (mean [ $\pm \mathrm{SD}] 46.12 \pm 10.84$ years); the majority of the sample was composed of women (69\%). Participant-caregivers
TABLE 4

Psychometric qualities of the Sherbrooke Observation Scale of Patient-Centered Care

\begin{tabular}{|c|c|c|c|}
\hline Video & $\begin{array}{c}\text { Cronbach's } \\
\text { alpha coefficient } \\
\text { (variance) }\end{array}$ & $\begin{array}{l}\text { Intraclass coefficient } \\
\qquad(95 \% \mathrm{Cl})\end{array}$ & Content validity \\
\hline 1 & $0.76(0.54)$ & $0.84(0.75-0.90)$ & \multirow{6}{*}{$\begin{array}{l}\text { Considered to be } \\
\text { satisfactory by } \\
\text { the expert panel } \\
\text { committee }\end{array}$} \\
\hline 2 & $0.77(0.68)$ & $0.86(0.77-0.91)$ & \\
\hline 3 & $0.81(0.71)$ & $0.89(0.83-0.94)$ & \\
\hline 4 & $0.81(0.81)$ & $0.91(0.86-0.95)$ & \\
\hline 5 & $0.76(0.67)$ & $0.88(0.81-0.93)$ & \\
\hline All & $0.88(0.37)$ & $0.93(0.89-0.96)$ & \\
\hline
\end{tabular}

were recruited from different hospitals and clinics of the province of Quebec. Two groups were included in the present study: nurses and physicians. Table 3 summarizes the characteristics of these participant-caregivers.

\section{Content validation}

Content validation refers to the completeness and the relevance of each item of an instrument $(34,40)$. According to a consensus obtained by the expert panel, content validity of the SOS-PCC was satisfactory for a population of French nurses and physicians (34). In fact, the experts concluded that all videos were representative of real patients with chronic pain and that the SOS-PCC accurately reflected the actual concept of PCC highlighted by the literature. The content of the final versions of each video are presented in Table 1 . The final version of the SOS-PCC contains nine items distributed among four dimensions: biopsychosocial perspective (three items); patient-as-person (two items); sharing power and responsibility (two items); and therapeutic alliance (two items). Table 2 summarizes this final version.

\section{Internal consistency}

Internal consistency indicates the strength with which each statement of the research instrument is related to the other statements and reflects the degree of homogeneity of the instrument $(34,41)$. To calculate the internal consistency of the SOS-PCC, the average scores given by the three observers for each participant-caregiver were used. The internal consistency was calculated for each video and the mean score of all videos. Table 4 shows the Cronbach's alpha coefficients and variance. According to Nunnaly (42), the threshold for good internal consistency is 0.70 . Thus, our results show a good internal consistency, with Cronbach's alpha coefficients ranging from 0.76 to 0.88 .

\section{Inter-rater reliability}

Inter-rater reliability refers to the consistency found in the assessment of multiple raters observing the same situation $(41,43)$. ICCs were used to evaluate the inter-rater reliability. ICCs were calculated for each video and for the mean score of all videos (Table 4). Our results showed good inter-rater reliability (44).

\section{DISCUSSION}

The purpose of the present study was to develop and validate an observation scale (SOS-PCC) to assess the use of PCC in caregivers (nurses and physicians), using standardized videos of real patients with chronic pain in an experimental clinical session. Our results showed that the SOS-PCC was valid and reliable in a French population of nurses and physicians working with chronic pain patients, and that the five videos have a good content validity.

The development of the SOS-PCC followed a rigorous process according to the recommendations of Streiner and Norman (34). As previously mentioned, we began with a review of the literature to define the concept of PCC. The SOS-PCC was pretested with a sample of five participant-caregivers. The participant-caregivers explained the support and the management they would provide after watching 
each video. The pretest showed that three external observers were able to score all nine items of the SOS-PCC after viewing the records of these participant-caregivers. Using a pretest is a good procedure to verify whether an instrument is clearly written and understandable (45). A larger sample of 10 to 40 participants is recommended to realise this step (46), but given the limited number of subjects in the target population, only five participant-caregivers took part in the pretest. However, the comments of these participant-caregivers were very helpful to improve the SOS-PCC.

The SOS-PCC displays good psychometric qualities. First, it is recommended to evaluate the content validity of a new instrument (47). The items were drawn from a consistent literature review, making our instrument complete. According to the expert panel, the videos case scenarios are authentic and all items of the SOS-PCC are comprehensive and relevant. These qualitative results suggest a good content validity. Moreover, the panel was composed of seven interdisciplinary experts in the health care field. These professionals have complementary expertise, as recommended $(48,49)$. Regarding reliability, internal consistency and inter-rater reliability were analyzed. The internal consistency for the mean scores is good, which suggest that items correlates with each other and with the total score. For the inter-rater reliability, our results show that the SOS-PCC can elicit similar judgements from different observers for the same situation. Having provided training for the three observers helped to reduced the risk of bias (34). Good inter-rater reliability is crucial for the SOSPCC to provide an accurate description of approach style.

There are some limitations to the present study. First, it would have been interesting to compare our new instrument with another observation scale. Some observation scales exist to measure PCC behaviour (50), but none evaluates all the four dimensions of PCC as defined in the conceptual model of Hudon et al (11). More studies with other samples of caregivers, such as physiotherapists, occupational therapists and psychologists, could analyze the validity of the SOS-PCC with other populations. Further research may also be necessary to evaluate other aspects of the validity, such as construct, discriminant or predictive validity. There is a possibility of social desirability bias, because caregivers-participants may have changed their behaviour because they

\section{REFERENCES}

1. Elzahaf RA, Tashani OA, Unsworth BA, Johnson MI.

The prevalence of chronic an analysis of countries with a Human Development Index less than 0.9: A systematic review without meta-analysis. Curr Med Res Opin 2012;28:1221-9.

2. Van Den Kerkhof EG, Hopman WM, Towheed TE, Anastassiades TP, Goldstein DH; Canadian Multicenter Osteoporis Study Research Group. The impact of sampling and measurement on the prevalence of self-reported pain in Canada. Pain Res Manag 2003;8:157-63.

3. Moulin DE, Clark AJ, Speechley M, Morley-Forster MK. Chronic pain in Canada - prevalence, treatment, impact and the role of opiod analgesia. Pain Res Manage 2002;7:179-84

4. Gureje O, Simon GE, Von Korff M. Persistent pain and well-being: A World Health Organization study in primary care. JAMA 1998;280:147-51.

5. Varrassi G, Raffaeli W, Marinangeli F, et al. Epidemiology and treatment of pain in Italy: Part I. Eur J Pain Supp 2008;2:44-6.

6. Azevedo LF, Costa-Pereira A, Mendonca L, Dias CC, Castro-Lopes JM. Chronic pain and health services utilization. Med Care 2013;51:859-69.

7. Gaskin DJ, Richard P. The economic costs of pain in the United States. J Pain 2012;13:715-24.

8. Pizzo PA, Clark NM. Alleviating suffering 101 - Pain relief in the United States. N Engl J Med 2012;366:197-9.

9. Jacobson L, Mariano AJ. General considerations of chronic pain. Bonica's Management of Pain, 2001, 241-54.

10. Carter J, Watson AC, Sminkey PV. Pain management: Screening and assessment of pain as part of a comprehensive case management process. Prof Case Manag 2014;19:126-34.

11. Hudon C, Fortin M, Haggerty JL, Lambert M, Poitras M. Measuring patients' perceptions of patient-centered care: A systematic review of tools for family medicine. Ann Fam Med 2011;9:155-64. were being observed. However, efforts were made to minimize that effect, such as not having specified the main variable of the study. The halo effect could also introduce a bias because the scores given by the observers can be influenced by their general impression of the caregiverparticipant; however, the presence of three observers can reduced the risk of such bias (34). Another limitation was the fact that our study included a convenience sample of caregivers (nurses and physicians) who were likely interested in pain management, which could have affected our results. However, we recruited participant-caregivers from different cities and clinical environments to increase the variability.

\section{CONCLUSION}

To our knowledge, the SOS-PCC is the first instrument available in French to assess the PCC behaviour of both nurses and physicians using videos of real patients with chronic pain. Instruments with good psychometric properties are necessary to measure PCC. Indeed, we used a rigorous development process that enabled us to create authentic videos and a relevant observation scale. Our results demonstrated that the psychometric qualities of this observation tool are good. These videos and the SOS-PCC can be used to evaluate the effectiveness of educational interventions and to better understand the underutilization of PCC in clinical environment. Future studies will need to assess this instrument with other populations of caregivers.

ACKNOWLEDGEMENTS: E Paul-Savoie has a doctoral scholarship from the Canadian Institutes of Health Research. P Bourgault was at the time of the study a Junior 1 Clinician Investigator with the Quebec Fund for Health Research (FRQS), and a researcher at the Centre de recherche $d u$ Centre hospitalier universitaire de Sherbrooke (CR-CHUS). E Gosselin has a doctoral scholarship from the Réseau de recherche en interventions en sciences infirmières du Québec. S Potvin is a Junior 1 Young Investigator from the FRQS, and is supported by the Centre de recherche de l'Institut universitaire en santé mentale de Montréal and the Louis-H Lafontaine Hospital Foundation. S Lafrenaye is supported by the medicine and health science faculty of the Université de Sherbrooke and a researcher at the CR-CHUS.

DISCLOSURES: The authors have no conflicts of interest to declare.

12. Mead N, Bower P. Patient-centredness: A conceptual framework and review of the empirical literature. Soc Sci Med 2000;51:1087-110.

13. Stewart MA. Effective physician-patient communication and health outcomes: A review. Can Med Assoc J;152:1423-33.

14. McCormack B, McCance T. Developing a conceptual framework for person-centred nursing. J Adv Nurs 2006;56:472-9.

15. Cvengros JA, Christensen AJ, Hillis SL, Rosenthal GE. Patient and physician attitudes in the health care context: Attitudinal symmetry predicts patient satisfaction and adherence. Ann Behav Med 2007;33:3:262-8.

16. Epstein RM, Franks P, Fiscella K, et al. Measuring patient-centered communication in patient-physician consultations: Theoretical and practical issues. Soc Sci Med 2005;61:1516-28.

17. Robinson JH, Callister LC, Berry JA, Dearing KA. Patient-centered care and adherence: Definitions and applications to improve outcomes. J Am Acad Nurse Pract 2008;20:12:600-7.

18. Stewart M, Brown JB, Donner A, et al. The impact of patient-centered care on outcomes. J Fam Pract 2000;49:9:796-804.

19. Wanzer MB, Booth-Butterfield M, Gruber K. Perceptions of health care providers' communication: Relationships between patient-centered communication and satisfaction. Health Comm 2004; $16: 363-84$

20. Alamo MM, Moral RR, de Torres LAP. Evaluation of a patient-centred approach in generalized musculoskeletal chronic pain/fibromyalgia patients in primary care. Patient Educ Couns 2002:48:23-31.

21. Monsivais DB, Engebretson JC. Cultural Cues: Review of qualitative evidence of patient-centered care in patients with nonmalignant chronic pain. Rehab Nurs 2011;36:166-71.

22. Coulmont M, Roy C, Dumas L. Patient-centered approach to care pay off? A cost-benefit analysis. Health Care Manag 2013;32:1:87-95 
23. Little P, Everitt H, Williamson I, et al. Observational study of effect of patient centredness and positive approach on outcomes of general practice consultations. BMJ 2001;323:908-11.

24. Parsons S, Harding G, Breen A, et al. Will shared decision making between patient with chronic musculoskeletal pain and physiotherapists, osteopaths and chiropractors improve patient care? Fam Pract 2012;29:203-12.

25. Zandbelt LC, Smets EM, Oorf FJ, Godfried MH, de Haes HC. Determinants of physicians' patient-centred behaviour in the medical specialist encounter. Soc Sci Med 2006;63:899-910.

26. Bensing JM, Tromp F, van Dulmen S, van den Brink-Muinen A, Verheul W, Schellevis FG. Shifts in doctor-patient communication between 1986 and 2002: A study of videotaped General Practice consultations with hypertension patients. BMC Fam Prac 2006;7:62.

27. Haidet P, Dains JE, Paterniti DA, et al. Medical student attitudes toward the doctor-patient relationship. Med Educ 2002;36:568-74.

28. Childs J. Clinical resource centers in nursing programs. Nurse Educ 2002;27:232-5

29. Peteani LA. Enhancing clinical practice and education with high-fidelity human patient simulators. Nurse Educ 2004;29:25-30.

30. Tamblyn R. Use of standardized patients in the assessment of medical practice. CMAJ 1998;158:205-7.

31. McWilliams P, Botwinski C. Developing a successful nursing objective structured clinical examination. J Nurs Educ 2010;49:36-41.

32. Leplege A, Gzil F, Cammelli M, Lefeve C, Pachoud B, Ville I. Person-centredness: Conceptual and historical perspectives. Disabil Rehabil 2007;29:1555-65.

33. Vessey J, Huss K. Using standardized patients in advanced practice nursing education. J Prof Nurs 2002;18:29-35.

34. Streiner DL, Norman GR. Health Measurement Scales: A practical Guide to Their Development and Use, 4th edn. Oxford: Oxford University Press, 2008.

35. Bower P. Understanding patients: Implicit personality theory and the general practitioner. Br J Med Psych 1998;71:153-63.

36. Brearly S. Patient participation: The literature, 1990. London: Scutari Press.

37. Gottlieb LN, Feeley N. La collaboration infirmière-patient : un partenariat complexe, 2007. Montréal : Chenelière Éducation.
38. Koehler WF, Fottler MD, Swan JE. Physician-patient satisfaction: Equity in the health services encounter. Med Care Rev 1992;49:455-84.

39. Crow R, Gage H, Hampson S, Hart J, Kimber A, Thomas H. The role of expectancies in the placebo effect and their use in the delivery of health care: A systematic review. Health Tech Assess 1999;3:1-96.

40. Anthoine E, Moret L, Regnault A, Sbille V, Hardouin JB. Sample size used to validate a scale: A review of publications on newlydeveloped patient reported outcomes measures. Health Qual Life Outcomes 2014;12:176.

41. Grove SK, Burns N, Gray JR. The Practice of Nursing Research, 7th edn. St Louis: Saunders, 2012.

42. Nunnaly J. Psychometric Theory. New York: McGraw-Hill, 1978.

43. Polit D, Beck C. Nursing Research: Generating and Assessing Evidence for Nursing Practice, 8th edn. Philadelphie: Lippincott Williams \& Wilkins, 2008.

44. Landis JR, Koch GG. The measurement of observer agreement for categorical data. Biometrics 1977;33:159-74.

45. Vallerand RJ. Vers une méthodologie de validation transculturelle de questionnaires psychologiques : implications pour la recherche en langue française. Psychologie Canadienne 1989;30:662-80.

46. Beaton DE, Bombardier C, Guillemin F, Ferraz MB. Guidelines for the process of cross-cultural adaptation of self-report measures. Spine 2000;25:3186-91.

47. Gélinas C, Loiselle CG, LeMay S, Ranger M, Bouchard E, McCormack D. Theoretical, psychometric, and pragmatic issues in pain measurement. Pain Manage Nurs 2008;9:120-30.

48. Grant JS, Davis LL. Selection and use of content experts for instrument development. Res Nurs Health 1997;20:269-74.

49. Waltz CF, Strickland OL, Lenz ER. Measurement in Nursing and Health Research, 3rd edn. New York: Springer Publishing Company, 2005.

50. Mead N, Bower P. Measuring patient-centredness: A comparison of three observation-based instruments. Patient Educ Couns 2002;39:71-80. 


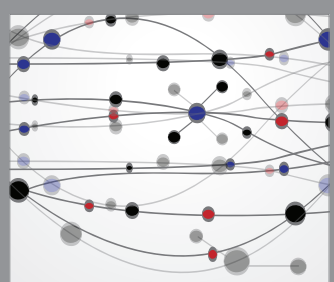

The Scientific World Journal
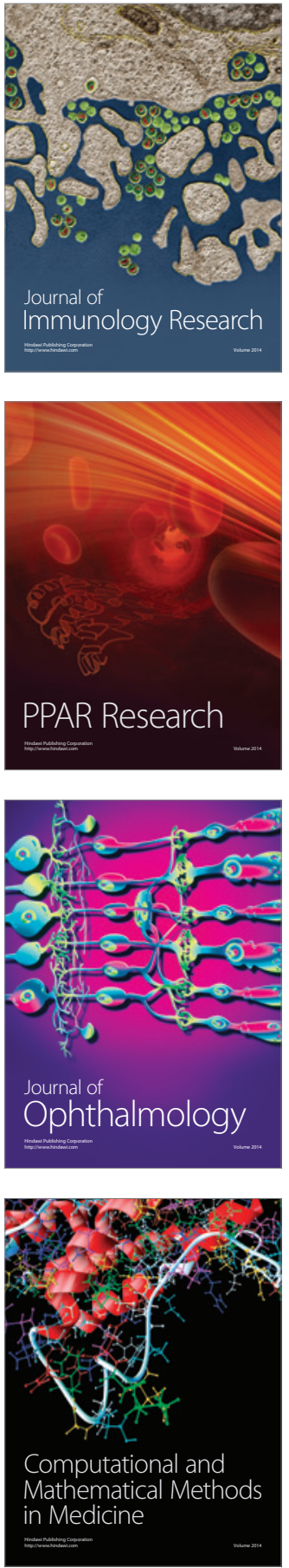

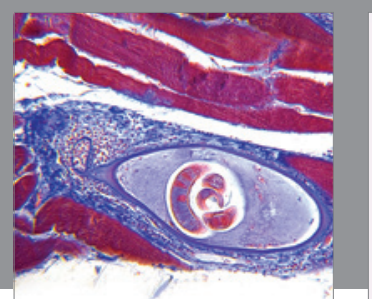

Gastroenterology Research and Practice

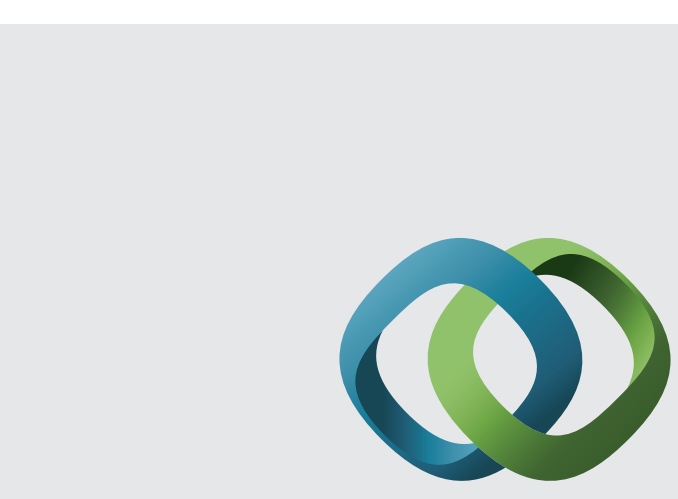

\section{Hindawi}

Submit your manuscripts at

http://www.hindawi.com
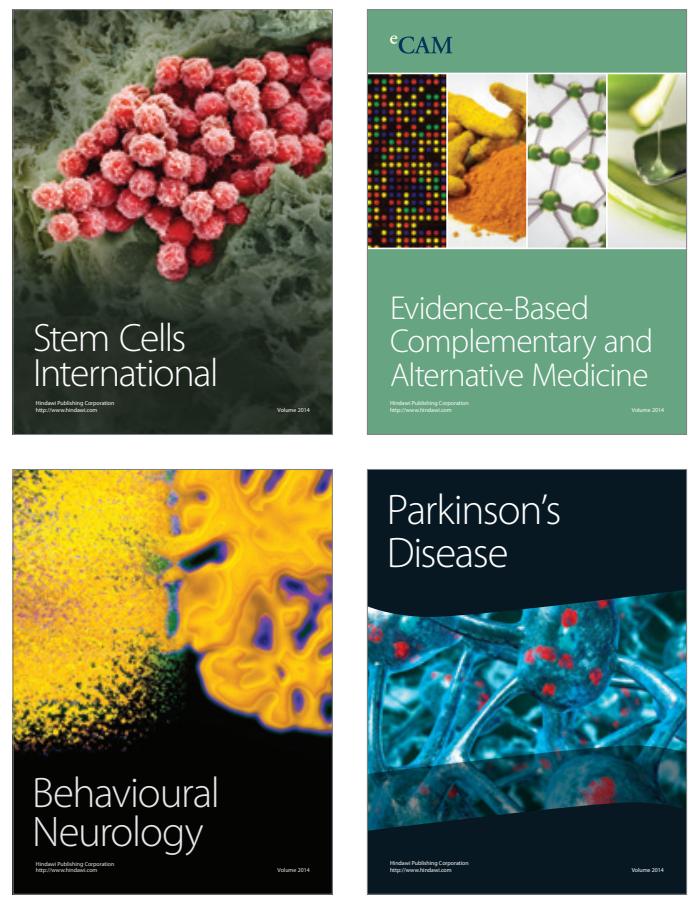
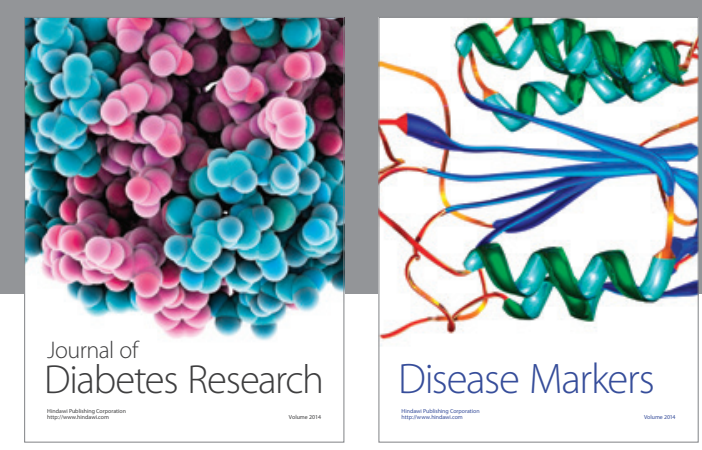

Disease Markers
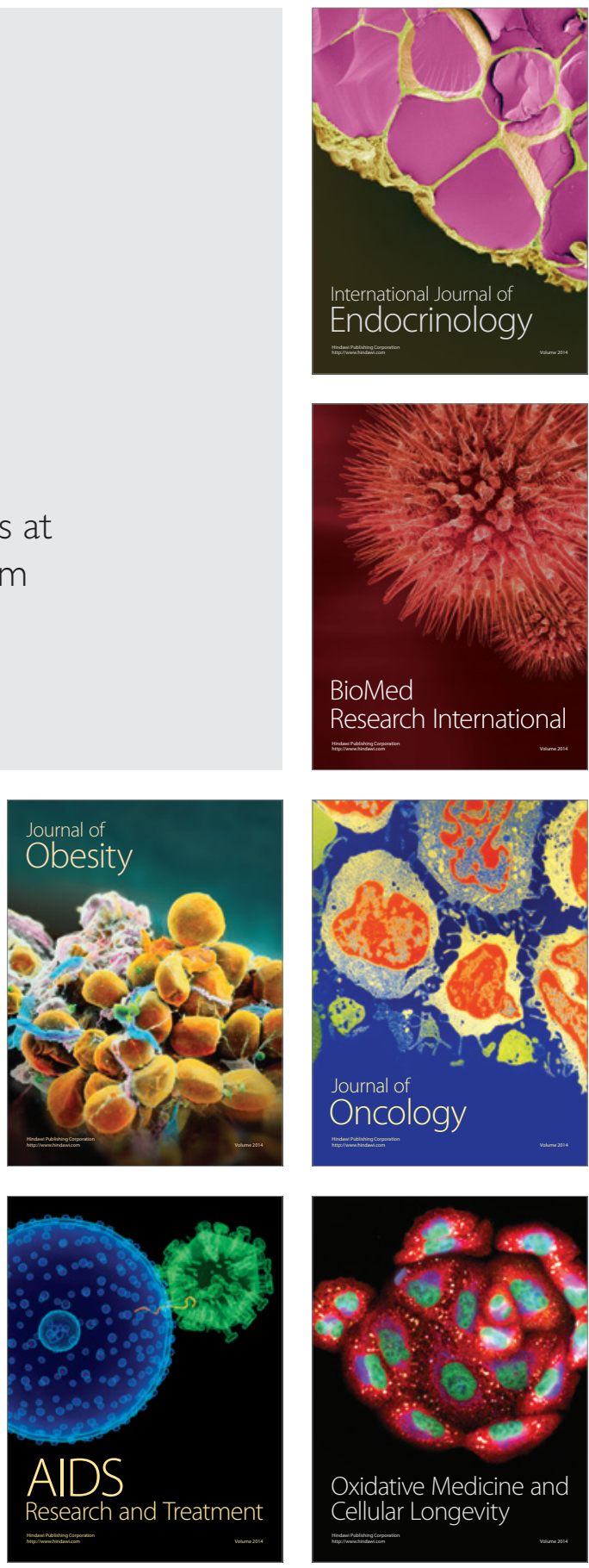